Human Embryonic and Fetal Death

Edited by I H Porter and E B Hook. (Pp xvi + 371; figures + tables.) New York, London: Academic Press. 1980.

This book is based upon the proceedings of the Tenth Annual Birth Defects Institute Symposium held in 1979 and fulfils its stated aim of bringing together data on human fetal loss. It deals in most detail with the epidemiology of early reproductive loss, but also includes useful information on perinatal loss associated with various genetic and environmental factors. The distinguished contributors are mainly from North America with Eva Alberman, Eve Roman, and Susan Harlap representing the rest of the world.

The first chapter by the editors is particularly helpful in that it summarises and comments on the various chapters in the rest of the book and provides references which are not mentioned by others.

In a book entitled Human Embryonic and Fetal Death there is a surprising amount of animal datathree whole chapters.

Particularly interesting chapters for the clinical geneticist are the one by Fantel et al, which deals mainly with embryonic and fetal phenotypes of spontaneous abortions, the one by Abby LippmanHand on genetic counselling of couples who have had spontaneous abortion, and the one by Elias and Simpson on evaluation and clinical management of patients at apparent increased risk for spontaneous abortion. The latter possibly dealt in too little detail with the important topic of maternal disease and fetal death on the grounds that such diseases more often caused third trimester problems.

The book ends with a masterly chapter by Josef Warkany putting teratology into perspective by examining its history and suggesting lines of investigation for the future.

There can be few criticisms of a book so packed with valuable data and references, but $I$ found the chapters on infections, radiation, and alcohol as causes of reproductive loss too brief, although this may reflect our lack of knowledge and work in these areas.

Throughout the book references are given in the brief form of name and journal only, and by now accustomed to the title of the paper in references $I$ would have preferred the fuller, more informative, form.
This book is certainly to be recommended as a valuable reference source for anyone planning studies on human reproductive loss and should be on the shelves of the library in medical genetics departments.

\section{Dian DonnaI}

\section{Chromosomal Variation in Man. A Catalog of Chromosomal Variants and Anomalies}

3rd ed. By Digamber S Borgaonkar. (Pp xxxiii + 714; figures + tables). New York: Alan R Liss. 1980.

This book, like the two earlier editions, is a catalogue of authors who have published papers relating to chromosome disorders. The information has been arranged in a logical order according to chromosome number, arm, band, and sub-band. The authors have been listed alphabetically within each category. Inevitably, such a reference finder dates quickly because of the delay in publication. Nevertheless, the arrangement of the information is such that it lends itself to frequent use in the cytogenetics laboratory.

The third edition of this book follows the format of the previous volumes and comprises three main sections: structural chromosome variations, numerical anomalies, and chromosomal breakage syndromes. The three sections have been expanded, especially the part dealing with structural variations since, with the increasingly sophisticated techniques available for chromosome identification, many more cases of this type have been reported.

The second part of the book which deals with numerical anomalies involving whole chromosomes is almost by definition self-limiting, but a number of useful sources of information have been included.

The third section remains largely as in the earlier editions. Included for the first time are two appendices, the first of which comprises a list of confirmed and tentative positions of gene loci, together with a list of chromosomally mutant cell lines available for cell hybridisation studies. While such information is of general interest to clinical cytogeneticists it more obviously caters for those involved in gene mapping. The second appendix should be of more interest to the cytogeneticist since it contains clinical details of syndromes caused by partial and complete chromosome aneuploidy. Each syndrome has been dealt with succinctly and with reference to the more frequently occurring phenotypic stigmata of the 